OPEN ACCESS

Edited by:

Jose R. Pineda,

University of the Basque

Country, Spain

Reviewed by:

Sergey Sedyh,

Institute of Chemical Biology and Fundamental Medicine (RAS), Russia

Abhimanyu Thakur,

University of Chicago, United States

${ }^{*}$ Correspondence:

Zhiming LU

luzhimingsdu@163.com

Lei Yang

1793152903@qq.com

Specialty section:

This article was submitted to

Neuro-Oncology and

Neurosurgical Oncology,

a section of the journal

Frontiers in Oncology

Received: 30 June 2021 Accepted: 20 September 2021 Published: 13 October 2021

Citation:

Wu X, Wang $X$, Wang J, Hao Y, Liu F, Wang $X$, Yang L and Lu Z (2021)

The Roles of Exosomes as Future

Therapeutic Agents and

Diagnostic Tools for Glioma.

Front. Oncol. 11:733529.

doi: 10.3389/fonc.2021.733529

\section{The Roles of Exosomes as Future Therapeutic Agents and Diagnostic Tools for Glioma}

\author{
Xiaoben $W u^{1}$, Xingbang Wang ${ }^{2}$, Jing Wang ${ }^{1}$, Yingying Hao ${ }^{1}$, Fang Liu ${ }^{1}$, Xin Wang ${ }^{1}$, \\ Lei Yang ${ }^{3 *}$ and Zhiming $\mathrm{Lu}^{1 *}$ \\ ${ }^{1}$ Department of Clinical Laboratory, Shandong Provincial Hospital Affiliated to Shandong First Medical University, \\ Jinan, China, ${ }^{2}$ Department of Neurology, Qilu Hospital, Shandong University, Jinan, China, ${ }^{3}$ Department of Medical \\ Engineering, Shandong Provincial Hospital Affiliated to Shandong First Medical University, Jinan, China
}

Glioma is a common type of tumor originating in the brain. Glioma develops in the gluey supporting cells (glial cells) that surround and support nerve cells. Exosomes are extracellular vesicles that contain microRNAs, messenger RNA, and proteins. Exosomes are the most prominent mediators of intercellular communication, regulating, instructing, and re-educating their surrounding milieu targeting different organs. As exosomes' diameter is in the nano range, the ability to cross the blood-brain barrier, a crucial obstacle in developing therapeutics against brain diseases, including glioma, makes the exosomes a potential candidate for delivering therapeutic agents for targeting malignant glioma. This review communicates the current knowledge of exosomes' significant roles that make them crucial future therapeutic agents and diagnostic tools for glioma.

Keywords: exosomes, glioma, diagnostic biomarker, prognostic biomarker, treatment

\section{INTRODUCTION}

Gliomas are the highest known primary malignant tumor that affects the brain. Among all the gliomas, glioblastoma (GBM) is the most prevalent type among all other types. It occupies $70 \%$ of all gliomas and has a median overall survival of 15 months (1). The United States' incident rate is 3.20 per 100,000 , and GBM handles $60 \%-70 \%$ of malignant glioma $(2,3)$. Glioma is the third highest cause of cancer deaths in patients aged 15 and 34 years, which is responsible for $2.5 \%$ of the worldwide cancer fatality rate. Glioblastoma multiforme is $50 \%$ of gliomas, with a higher prevalence of patients over 65 years of age (4).

Abbreviations: GBM, glioblastoma; TMZ, trimetazidine; EMT, epithelial-mesenchymal transition; MDSCs, myeloid-derived suppressor cells; MCP-3, monocyte chemotactic protein 3; CXCL1, chemokine (C-X-C motif) ligand 1; GSCs, glioblastoma stem cells; TME, tumor microenvironment; EMT, epithelial-mesenchymal transition; DNA, deoxyribonucleic acid; RNA, ribonucleic acid; HBMEC, human brain microvascular endothelial cell; CADM1, cell adhesion molecule 1; STAT3, signal transducer and activator of transcription 3; CAB39, calcium-binding protein 39; AMPK, prime-AMP-activated protein kinase; FBXW7, F-box and WD repeat domain containing 7; DKK3, Dickkopf homolog 3; BBB, blood-brain barrier; circNFIX, circular RNA nuclear factor I X; SPION, superparamagnetic iron oxide nanoparticles; EZH2, enhancer of zeste homolog 2; GDEs, genes with different expression levels; EVs, extracellular vesicles; MCP-3, monocyte chemotactic protein; AGAP-2, ArfGAP with GTPase; ANK repeat, and PH domain-containing protein 2, TiO2-CTFE-AuNIs, titanium dioxide $\left(\mathrm{TiO}_{2}\right)$ columnar thin film (CTF), coupled with gold nanoislands (AuNIs); BIGH3, beta Ig-H3. 
Multiple occurrences such as high growth rate, widespread invasion, and genetic variations are characteristics of gliomas. The drug resistance of GBM, the poor prognosis of patients who harbor glioma, is significantly linked to the lack of insight into the molecular facts related to the initiation of glioma and the absence of sensitive diagnosis and accurate therapeutic agents (5). The glioma microenvironment comprises different cells other than tumor cells, such as astrocytes, microglia, endothelial cells, and immune cells. Currently, trimetazidine (TMZ) is the primary chemotherapy drug for GBM (6). Patients with GBM have relatively high treatment resistance, resulting in decreasing overall survival (7). Immunotherapy inhibits the immune checkpoint receptor of programmed cell protein 1 (PD-1), and bevacizumab that inhibits the vascular endothelial growth factor is now being studied to enhance the treatment outcome of patients treated with GBM, which is the most prevalent glioma type (8). The determination of GBM is primarily focused on imaging methods and biopsies of tissues. However, imaging methods cannot reliably distinguish lesions induced by tumor development from treatment-related pseudoprogression lesions that mimic tumor progression and may typically resolve with time (9). Liquid biopsies allow identifying circulating biomarkers and offer the advantage of being non-invasive, thus enabling serial sampling and tracking possible structural reforms in the tumor during therapy (10).

At present, the critical testing techniques for diagnosing gliomas are based on neurological tests and neuroimaging procedures are sometimes performed when gliomas are at the advanced level (11). Exosomes are extracellular vesicles first identified 30 years ago. They have since been connected to cell-cell communication, disease propagation, and drug development (12). Those exosomes comprise different bioactive molecules, such as microRNAs (miRNAs), messenger RNA (mRNA), and other vital protein compounds (13).

Exosomes are critical for cellular signaling in normal physiology and pathological conditions, most notably in cancer. Exosomes are potent progenitors capable of changing target cell phenotypes, most notably during carcinogenesis and development, by altering tumor microenvironments and assisting in establishing the pre-metastatic niche. Numerous features of exosomes point to them as a new method for identifying cancer biomarkers for early diagnosis and therapeutic targets and for utilizing exosomes' inherent and modified properties as therapeutic tools to slow down disease development (14). The blood-brain barrier (BBB) protects the central nervous system, supplies nourishment, regulates homeostasis, and allows the brain and the rest of the human body to communicate through the serum. Because of the complex structure of the $\mathrm{BBB}$, drug administration in the brain is a significant problem, necessitating the discovery of innovative methods to achieve improved drug delivery in the brain, either invasively or non-invasively (15). To solve the issue mentioned above, different studies have been proposed to use exosomes to deal with this issue due to their nano size. Also, various studies revealed that exosomes are highly or lowly expressed in different cancers, including glioma. In addition, exosomes are also involved in other main cancer events, such as cancer initiation and progression of various cancers (16); however, this active status made exosomes potential therapeutic and biomarkers tools for glioma (17). The primary purpose of this review is to highlight the roles of exosomes as future therapeutic agents and diagnostic tools for glioma

\section{EXOSOME'S BIOLOGY}

Exosomes are extracellular vesicles with a diameter of around $30-100 \mathrm{~nm}$ with a bilayer membrane $(18,19)$. Exosomes include several cargo types comprising proteins, lipids, enzymes, transcriptional factors, DNA fragments, mRNAs, micro-RNAs, and Long non-coding RNA (lncRNAs) (20, 21). Exosomes are released by different cell types, such as erythrocytes, platelets, lymphocytes, dendritic cells (DCs), adipocytes, fibroblasts, brain cells, stem cells, and cancer cells. Exosomes are detected in biofluids, including blood, plasma, urine, Cerebrospinal fluid (CSF), milk, amniotic fluid, malignant ascites, saliva, and synovial fluid (Figure 1). They play a significant part in the signals of normal and pathological processes in communication

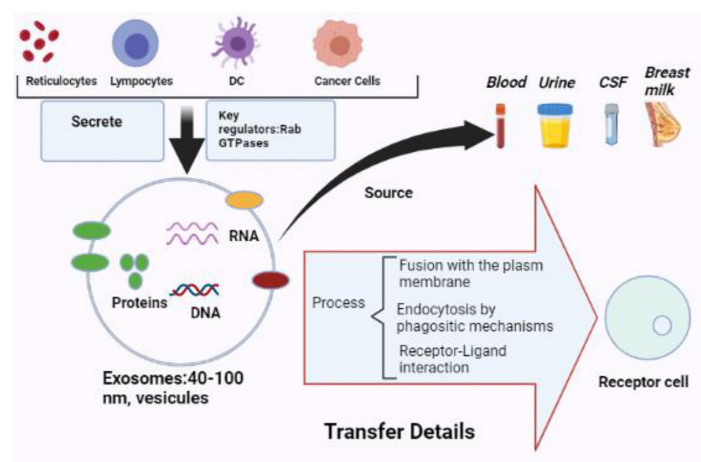

FIGURE 1 | The biology of exosomes. Exosomes are vesicles with a diameter of 40 to $100 \mathrm{~nm}$ that may be produced by various cells and extracted from multiple bodily fluids. Exosomes may provide information to receptor cells via plasma membrane fusion, phagocytic endocytosis, or cell-receptor contact (BioRender.com was used to create this figure). 
between cells and transporting substances such as proteins and RNAs from donor cells to recipient cells $(16,22,23)$.

The biogenesis of exosomes occurs by inward budding of the plasma membrane that forms the endosome vesicle and the multivesicular bodies (MVBs). MVBs fuse with lysosomes, degrade or fuse with the plasma membrane, and create exosomes released from cells into extracellular space (22). Late endosomal structures containing dozens of Intraluminal Vesicles (ILVs) are known as MVBs, which are eventually transported to the trans-Golgi network for endosome recycling, delivered to lysosomes for degradation of all carried material, or fused with the plasma membrane and release exosomes into the extracellular space; this process is facilitated by Rab GTPase, such as RAB11 and RAB35, which release exosomes enriched with flotillin and other cell-specific proteins (24). Thus, exosome biogenesis and secretion require forming an endosomal-sorting complex required for transport (ESCRT) (25). ESCRT comprises four complexes (ESCRT-0, ESCRT-I, ESCRT-II, and ESCRT-III) and associated proteins (VPS4, Tsg101, and ALIX). ESCRT-0 sorts ubiquitinated cargo proteins into the lipid domain; ESCRTI and ESCRT-II induce membrane deformation to form the stable membrane neck, and recruitment of the Vps4 complex to ESCRT-III drives vesicle neck scission and the dissociation and recycling of the ESCRT-III complex $(26,27)$.

A broad range of research has indicated an ESCRT-independent route in the exosome synthesis and carrier packing of lipids and related proteins, including tetraspanine (28). In opposition to ESCRT-sorted proteins, the loading of RNA into exosomes becomes lipid-mediated, reliant on self-organizing fat and carrier motifs. Specific nucleotide sequences show improved phospholipid bilayer affinity that relies on variables such as lipid morphology, hydrophobic changes, and physiologically concentrated sphingosine within rafting membranes $(29,30)$. Lipid rafts are plasma membrane subdomains loaded in cholesterol, sphingolipids, and attached proteins of glycosyl-phosphatidylinositol (GPI) whose connection with proteins or compounds may help their release by the use of exosomes $(31,32)$. The availability on the limiting membrane of ceramide, lysophospholipid, and glycosphingolipid molecules promotes the impulsive entry method to create ILVs (33). The ceramide changes in the existence of ceramidase and sphingosine kinase into sphingosine and sphingosine phosphate and the continual stimulation of 1-phosphate sphingosine receptors on the limited membrane facilitate the kind of tetraspanin into ILV. Thirty-three, three-four tetraspanin is a cell surface protein superfamily member with four transmembrane domains. Tetraspanin organizes membrane microdomains termed TEMs with a broad range of transmembrane and cytosolic signaling proteins (34). As the first tetraspanin, CD63 works in ESCRTindependent ILV creation. Interestingly, the lack of an ESCRT machine did not prevent the formation of MVB vesicles in mammalian cells but led to decreased cargo processing and changes in ILV numbers and sizes (35), indicating that exosome biogenesis could be a synchronized process that involves ESCRTdependent and ESCR-independent pathways. The methods of exosome penetration into recipient cells have not been adequately explored. Nevertheless, it has been demonstrated that, according on the recipient cell type, exosomes penetrate target cells via fusion with the plasma membrane, macropinocytosis, phagocytosis, and clathrin-dependent endocytosis.

\section{THE ROLES OF EXOSOMES IN GLIOMA DEVELOPMENT}

Exosomes play a critical function in cell-cell communication by transporting bioactive materials from the donor cells to the receiving cells (36). Many pieces of research have revealed that cancer cells release more exosomes, both locally and at a distance, to share information with other cells (37). Cancerderived exosomes contribute to pre-metastatic milieu creation, tumor development, progression, immune evasion, angiogenesis, anti-apoptotic signaling, and treatment resistance throughout their bioactive cargo. Meanwhile, healthy cell exosomes such as DCs, B cells, and T cells significantly prevent tumor growth (38). To date, many miRNAs, lncRNAs, and proteins have played a vital role in the development of cancer. Therefore, exosomes may play a dual function in controlling, preventing, or encouraging the development of cancer, depending on their cell of origin and bioactive cargo (Figure 2).

It has been reported that over $48 \mathrm{~h}$, a single glioma cell secretes around 10,000 EVs (39). Glioma cell exosomes transport different chemicals than regular glial cell exosomes (40). Cancer effectors such as a mutant oncoprotein, oncogenic transcripts, and miRNAs are among the elements involved in tumor formation (28). In addition, exosomes enhance communication between cancer cells and the stromal cells surrounding them, resulting in either the tumorigenesis of apparently normal cells or a change in their behavior, which offers a favorable environment for the tumor to grow (41).

Angiogenesis is a critical event in glioma development, and glioma-delivered exosomes have been reported to play an essential role in this important event of glioma progression. For instance, a study that aimed to determine the processes of the glioma cell-affected angiogenesis noted that glioma cells might stimulate angiogenesis by transferring Linc-CCAT2 to endothelial cells through exosomes (42). Also, Lang HL et al. showed that gliomas stimulated angiogenesis by producing exosomes with high linc-POU3F3 (43); linc-POU3F3 has been reported to be involved in the development of glioma (43). On the other hand, a study showed that exosomes generated from hypoxic GBM cells relative to normoxic circumstances are effective inducers of angiogenesis in vivo. Moreover, they do the same in vitro via endothelial cell regulation, which increases tumor progression (44). Also, a study conducted by Xu Sun et al. noted that exosomes generated from glioma stem cells (GSCs) enhance endothelial cells' angiogenic capacity through the miR21/VEGF signaling pathway (45).

Moreover, different studies have revealed that exosomes are also involved in promoting and facilitating metastasis, which is a significant event in the progression and development of various cancers, including glioma. For example, Q. Cai et al. showed that miR-148a carried by exosomes facilitated cancer cell 


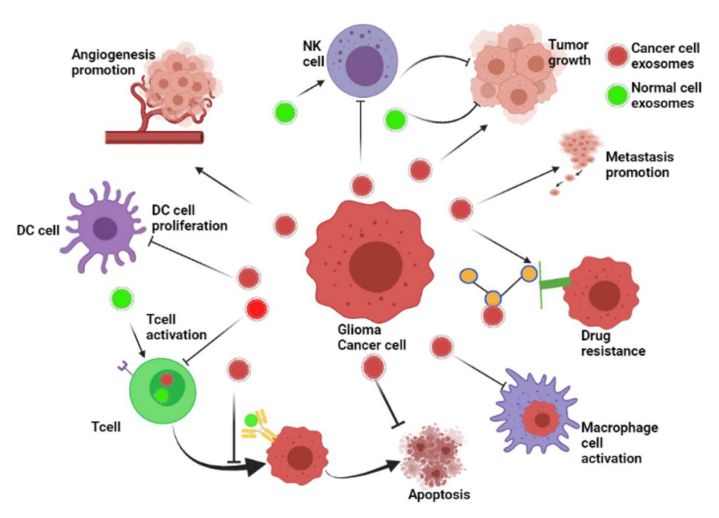

FIGURE 2 | The roles of exosomes in glioma's development. The role of exosomes in cancer progression. Cancer cell-derived exosomes influence the formation of the pre-metastatic microenvironment, tumor growth and advancement, immune escape, angiogenesis promotion, stopping of apoptosis, drug resistance, and metastasis. Besides, exosomes from healthy cells, including dendritic cells (DCs), B cells, and T cells, play a role in the inhibition of tumor growth (BioRender.com was used to create this figure).

proliferation and metastasis by directly targeting CADM1 to trigger the STAT3 pathway (46), which plays an essential role in the metastasis of different cancer types, including glioma (47). Also, Zhanjun Ma et al. found that U251 cell-derived exosomes promoted metastasis-related proteins such as MMP-2 and MMP-9 (48), which facilitated the development of glioma. Moreover, another study also showed that the exosome EpCAM promotes the metastasis of glioma by targeting the CD44 signaling molecule on the surface of glioma cells; this exosome influenced the progression of glioma (49).

On the other hand, another study by Karma R Pace et al. discovered that exosomal L1CAM enhances motility, proliferation, and invasion in GBM cells, adding to the intricacy of how exosomal L1CAM promotes cancer cells not just through soluble ectodomains but also by exosomes (50). Besides, by directly targeting FBXW7 and DKK3, Gang Peng and his colleagues found that exosomal miR-25-3p significantly promoted the proliferation and migration of glioma cells (51). Furthermore, a recent study revealed that exosomal microRNA671-3p increases cell proliferation in glioma by directly targeting CKAP4; this affected the proliferation and significantly increased glioma cell migration, facilitating glioma growth (52). Epithelialmesenchymal transition is another vital factor that plays a significant role in glioma progression, and exosomes have been reported to be involved in glioma's EMT. For instance, a study showed that exosomal microRNA-708 repression increases cell proliferation and EMT in glioma via promoting the SPHK2/ AKT/-catenin pathway (53). In addition, another study also discovered that TGF-1 treatment substantially increased miR$10 \mathrm{~b}$ expression in GBM cells, and miR-10b upregulation increases GBM cell proliferation, migration, and EMT; in contrast, miR-10b deletion has an opposite impact (54). Conclusively, the above facts show that exosomes play a crucial role in many critical glioma occurrences, such as cell proliferation, metastasis, angiogenesis, and EMT. More details about the involvement of exosomes in the progression of glioma are presented in Table $\mathbf{1 .}$

\section{THE APPLICATION OF EXOSOMES AS FUTURE BIOMARKERS AND THERAPEUTIC OPTIONS FOR GLIOMA}

\subsection{Exosomes as Biomarkers for Glioma}

GBMs are histologically varied tumors composed of many and different cell types. Notably, managing GBM is a significant problem for neurosurgeons. The current standard of care for GBM is magnetic resonance imaging (MRI) followed by surgery or brain biopsies. Both of these methods, however, have drawbacks (61).

Additionally, it is difficult to differentiate between tumor recurrence and postsurgical necrotic areas without histological investigation. On the other hand, collecting histology samples through immediate surgery or biopsies is time-consuming and hazardous, owing to the accompanying surgical risks. In addition, this is a one-time procedure with uncertain reliability due to the tumor's heterogeneity, so using exosomes would be the best option to overcome those drawbacks in the future (62).

TABLE 1 | Exosomes that are involved in glioma.

\begin{tabular}{|c|c|c|c|}
\hline Exosomes & Target & Outcome & References \\
\hline miR-9 & MYC and OCT4 & $\begin{array}{l}\text { Promotes tumorigenesis and } \\
\text { angiogenesis }\end{array}$ & (55) \\
\hline miR-1238 & $\begin{array}{l}\text { EGFR-PI3K-Akt- } \\
\text { mTOR }\end{array}$ & $\begin{array}{l}\text { Promotes proliferation, } \\
\text { migration, and TMZ resistance }\end{array}$ & (56) \\
\hline miR-148a & CADM1/STAT3 & $\begin{array}{l}\text { Promotes proliferation and } \\
\text { metastasis }\end{array}$ & (46) \\
\hline miR-1587 & Inhibiting NCOR1 & Increases tumorigenicity & (57) \\
\hline $\begin{array}{l}\text { MicroRNA- } \\
148 a-3 p\end{array}$ & Inhibiting ERRFI1 & Promotes tumor angiogenesis & (58) \\
\hline $\begin{array}{l}\text { MicroRNA- } \\
155-3 p\end{array}$ & Targeting Six1 & $\begin{array}{l}\text { Promotes glioma progression } \\
\text { and temozolomide }\end{array}$ & (59) \\
\hline $\begin{array}{l}\text { MicroRNA- } \\
6807-3 p\end{array}$ & $\begin{array}{l}\text { Targeting } \\
\text { downstream } \\
\text { DACH1 }\end{array}$ & $\begin{array}{l}\text { Promotes the tumorigenesis of } \\
\text { glioma }\end{array}$ & (60) \\
\hline
\end{tabular}

TMZ, trimetazidine. 
Different significant studies have been conducted to assess if exosomes can be used as diagnostic and prognostic biomarkers; for example, a study reported that exosomal miR-181 could be a potential biomarker for human glioma at its initial stage. Interestingly, detecting miR-181 high rates may be a promising alternative for diagnosing glioma, evaluating the World Health Organization grade of tumors, and guiding in glioma medical management (63). Subsequently, another research also noted that exosomal miR-124 was involved in different glioma events such as promoting angiogenesis and chemoresistance, and the same study also found that exosomal miR-124 is a potential diagnostic marker of glioma (64). However, the researchers did not stop to continue to do more in-depth studiess on how exosomes are suitable candidates for the diagnosis and prognosis of glioma. That is why a study conducted by Fengming Lan and his colleagues, which had the primary purpose of determining both the diagnostic and prognostic values of exosomal miR-301a in patients with glioma, reported that exosomal miR-301a could show both cancer status and some changes with pathological changes in human glioma, which made miR-301a an excellent candidate for the diagnostic and prognostic biomarkers of glioma (65).

Furthermore, another study reported that people who suffer from glioma had increased levels of miR-205 and had improved overall survival rates compared to those who had decreased expression levels of miR-205. In addition, the authors of the same study concluded that the exosomes mentioned above could significantly be a prognostic biomarker for patients with advanced pathological glioma grades; it can also be used as a potential biomarker for the same cancer (66). Moreover, another research that aimed to determine the predictive and diagnostic significance of exosomal miR-221/miR-222 found that the increased positive plasma of both miRNAs was paired with low survival rates. They also found that both miR-221 and miR-222 are valuable tools to reveal glioma (67). Subsequently, a study that aimed to determine the clinical significance and diagnostic value of miR-128 reported that the diagnostic odds ratio was considerably high; this meta-analysis study highlighted that miR128 could be a potentially non-invasive biomarker of glioma (68). In the meantime, the analysis of miR-21, miR-222, and miR-124-3p in serum exosomes in persons with glioma could provide a minimally invasive and revolutionary method to the differential diagnosis of glioma at their initiation in the brain and forecast glioma grade and non-glial metastases before surgery (69). Furthermore, it has also been revealed that the high rate of small RNU6-1, together with miR-320 and miR-574-3p, was found to be correlated with GBM IV diagnosis (70); more details are shown in Table 2.

By employing quantitative real-time PCR, Tan et al. determined HOTAIR expression in serum from $43 \mathrm{GBM}$ patients and 40 controls. It was found that HOTAIR levels were substantially high in serum samples from GBM patients than with matched controls. In addition, the expression of HOTAIR was found to be strongly associated with high-grade brain cancers, and Pearson's correlation analysis revealed a moderate association between serum and tumor HOTAIR
TABLE 2 | Various available exosomes considered as biomarkers for glioma.

\begin{tabular}{|c|c|c|}
\hline Exosomes & Roles in Glioma & References \\
\hline CircNFIX & $\begin{array}{l}\text { CircNFIX augments TMZ resistance in glioma by } \\
\text { sponging miR-132, indicating a possible prognostic } \\
\text { biomarker. }\end{array}$ & $(71)$ \\
\hline HOTAIR & $\begin{array}{l}\text { The levels of HOTAIR in tumor samples are much } \\
\text { higher than in normal samples, and this research } \\
\text { indicated that HOTAIR might be utilized as a } \\
\text { prognostic and diagnostic biomarker for glioma. }\end{array}$ & (72) \\
\hline miR-181 & $\begin{array}{l}\text { Detection of the level of miR181 family members } \\
\text { may be a potential method for glioma diagnosis, } \\
\text { determining the tumor WHO grade, and guiding } \\
\text { clinical treatment. }\end{array}$ & (63) \\
\hline miR-301a & $\begin{array}{l}\text { Patients with an advanced pathological grade (III or } \\
\text { IV) and an increased serum exosomal miR-301a } \\
\text { level revealed a more prolonged overall survival than } \\
\text { those with a lower level; this made mi-301a an ideal } \\
\text { prognostic and diagnostic biomarker for glioma. }\end{array}$ & (65) \\
\hline miR-205 & $\begin{array}{l}\text { Serum miR-205 levels were significantly increased in } \\
\text { postoperative samples over preoperative samples } \\
\text { and were reduced again during glioblastoma } \\
\text { recurrences. miR-205 expression is a novel and } \\
\text { valuable biomarker for diagnosing glioma and a } \\
\text { prognostic factor for those with a tumor at an } \\
\text { advanced pathological grade. }\end{array}$ & (66) \\
\hline miR-128 & $\begin{array}{l}\text { circulating miR-128 is a promising non-invasive } \\
\text { biomarker for diagnosing glioma. }\end{array}$ & (68) \\
\hline $\begin{array}{l}\text { miR-21, } \\
\text { miR-222, } \\
\text { and miR- } \\
124-3 p\end{array}$ & $\begin{array}{l}\text { miR-21, miR-222, and miR-124-3p in serum } \\
\text { exosomes of patients affected by gliomas can } \\
\text { provide a minimally invasive and innovative tool to } \\
\text { help the differential diagnosis of gliomas at their } \\
\text { onset in the brain and predict glioma grading and } \\
\text { non-glial metastases before surgery }\end{array}$ & (69) \\
\hline
\end{tabular}

TMZ, trimetazidine.

levels. As a result, serum HOTAIR can predict and diagnose GBM (72). Besides, another study performed on glioma patients found that exosomal CircNFIX levels were high in the serum of the patients resistant to TMZ, and CircNFIX high levels predicted poor prognosis, making it a potential prognostic biomarker for gliomas (71). Moreover, Chandran and colleagues conducted a study to explore extracellular plasma vesicles, and their research showed that Syndecan-1 is a critical biomarker for differentiating low- and high-grade gliomas (73). The tumorigenic epidermal growth factor receptor III is frequently overexpressed in high-grade glial brain tumors (EGFRvIII) (74). Combining both EGFRvIII and exosomes might be a good platform to create new effective biomarkers for glioma. For example, a study that had the main purpose of establishing a clinically adaptive protocol as a non-invasive diagnostic tool for EGFRvIII detection through serum exosomes found that the accuracy of EGFRvIII detection through exosomes was $80 \%$ for tissue EGFRvIII expression with an overall sensitivity and specificity of $81.58 \%$ and $79.31 \%$, respectively (75). This study concluded that using exosome-based liquid biopsy to assess EGFRvIII expression for high-grade glioma diagnosis is extremely promising. It may assist in distinguishing high-grade gliomas from infective demyelinating illnesses with comparable radiological features. 
Different advances have been made to produce new precision therapeutic and diagnostic tools for different types of cancer, including glioma. Theranostics is one of the new fast-expanding disciplines that combines nanotechnology's unique possibilities with customized medicine for substantially improving effectiveness with decreased off-target impacts by providing therapy for targeted tissues (76). In 2021, Batla S. Al-Sowayan et al. mentioned that diagnostic and forecast biomolecular profiles may be developed utilizing nanogenomics and artificial intelligence for breast tumors based on the exosome packed content instead of free circulating miRNA and other biomolecules, which is an integrated approach toward the discovery of practical therapeutic and diagnostic tools for various types of cancer including glioma (77). Moreover, another study found that using both learning machines and nanofluids that encapsulate exosomes distinguished cancer and precancer mice from healthy controls and pancreatic cancer patients from healthy controls. Furthermore, deep sequencing is based on new and sophisticated technologies that enable billions of nucleotides to be sequenced in one run. Using this technology is crucial in discovering not only therapeutic agents but also biomarkers for glioma. For example, using deep sequencing technology, Saeideh Ebrahimkhani et al. noted that serum exosomal miRNA signatures could accurately diagnose GBM preoperatively; this makes this exosomal miRNA signature a potential diagnostic biomarker for glioma (78). Altogether, the above-mentioned facts show that exosomes are potential candidates to be glioma biomarkers.

\subsection{Exosomes as Therapeutic Agents for Glioma}

Cancer treatment is one field that is developing at a very significant speed (17). Additionally, researchers realized that exosomes might also be involved in the treatment of glioma. For example, a study, which had the primary aim to evaluate whether marrow stromal cell (MSC) exosomes can be used as a vehicle for the delivery of anti-tumor miRNAs, found that transfected MSCs with miR-146b plasmid expression harvested MSC-released exosomes and intra-tumor injection of exosomes extracted from miR-146-expression and MSCs significantly decreased glioma development in the primary brain tumor in the used mouse model (79). Chemoresistance is another issue in treating different cancers, including glioma. Exosomes have been linked positively to this issue by restoring chemosensitivity. For example, the transmission of anti-miR-9 to resistant GBM cells restored the multidrug transmitter's function and attuned the GBM cells to TMZ, as shown by increased cell death and caspase activity. The findings showed the role of MSCs in the empirical distribution of synthetic anti-miR-9 in overcoming GBM cells' chemoresistance (80). Besides, exosomal transfer of long noncoding RNA SBF2-AS1 enhances chemoresistance to molozonide in GBM by secreting the oncogenic LincSBF2AS1-enriched exosomes (81). Yin J et al. showed that exosomal miR-1238 contributes more to the modulation of gained GBM chemoresistance; exosomal miR-1238 can induce the chemoresistance microenvironment of the tumor (82).
Furthermore, exosomes have been reported to be outstanding candidates to stop the tumor from spreading in various cancers, including glioma. For example, a study that aimed at determining the clinical roles and the regulatory mechanism of miR-454-3p in glioma found that regaining the expression of miR-454-3p inhibited significantly different features such as cell proliferation, migration, invasion, and autophagy in glioma, which made miR-454-3p be considered as a glioma tumor suppressor and a treatment agent for glioma (83). Moreover, another study reported that exosomal miR-451 impeded the proliferation, invasion, and apoptosis of GBM cells, and this study concluded that exosomal miRNA-451 could act as a tumor suppressor in human gliomas (84).

In the continuing movement of discovering new treatments for glioma, various studies have been conducted and showed that some exosomes could be potential therapeutic targets in glioma, which is regarded as an excellent cancer treatment approach. For instance, a study reported that the repression of miR-10b in the human glioma mouse model results in a more significant tumor progression decrease. Furthermore, their study briefly affirms the essential role of miR-10b in glioma initiation, unveiling the novel mechanism of miR-10b-mediated control and showing the likelihood of its potential use as a therapeutic target in glioma (85).

It has also been found that exosomal miR-34 can be used as a tumor suppressor for glioma by targeting two essential genes, c-Met and Notch (86). Also, it has been found that miR146a inhibits glioma growth by directly targeting and stopping the Notch1 pathway activity (87). Lei Yu et al. also reported that mesenchymal stem cells that transmitted miR-199a to the glioma cells by exosomes suppressed different important glioma features, such as cell proliferation, invasion, and migration. Besides, high expression of miR-199a in mesenchymal stem cells that restored TMZ chemosensitivity miR-199a also suppressed glioma by downregulating AGAP2 (88). Another study revealed that miR-1246, detected in the cerebrospinal fluid in patients suffering from GBM, could be a diagnostic biomarker. This study also noted that targeting microRNA-1246 may lead to anti-tumor immunotherapy (89). Also, another study reported that GSCs produced exosomes carrying Notch1 protein; when these exosomes were absorbed into non-GSC glioma cells, Notch1 transferred from GSC exosomes activated the Notch1 signaling pathway, increasing the stemness and tumorigenicity of these non-GSC glioma cells. In addition, GSC exosomes serve as information carriers, facilitating the dedifferentiation of non-GSC glioma cells into GSCs by conveying Notch1 protein and activating Notch1 signaling, maintaining the dynamic equilibrium state of GSCs in the tumor microenvironment. GSC exosomes and the Notch1 signaling pathway targeted to harm GSCs might be a unique method for GBM eradication that needs further exploration (Figure 3). The above facts show that continuous studies will improve the likelihood of exosomes to be used as future glioma treatments (90). More details concerning the roles of exosomes in the treatment of gliomas are summarized in Table 3. 


\subsubsection{Exosomes as a Crucial Delivery Method of Various Therapeutic Agents to Glioma Tumors}

Drug loading may be done, whether endogenously or exogenously (Figure 4). By employing normal cell culture procedures, endogenous or passive loading is carried out by overexpressing the RNA species or molecule of interest. This passive loading is facilitated by the cell's natural exosomal loading processes and results in exosomes that contain the medication before isolation. Exogenous or active loading starts with exosome collection. Then, it involves either co-incubation or electroporation of the exosomes with the drug, and afterwards, the exosomes can be safely delivered to the target cells (99).

To enhance the efficacy of cancer therapy, medicines must be delivered precisely to tumor cells. Clinically, medication delivery techniques based on nanotechnology are one of the most promising means to accomplish this task. Exosomes have been effectively utilized as medicinal and functional RNA delivery vectors for cancer treatments (100). Exosomes may be absorbed by cells and medicines such as therapeutic miRNAs and proteins that are securely transferred (101). For example, in 2018, Gang Jia and His colleagues firstly loaded super-paramagnetic iron oxide nanoparticles (SPIONs) and curcumin (Cur) into exosomes. They then conjugated the exosome membrane with neuropilin-1-targeted peptide by click chemistry to get gliomatargeting exosomes with imaging and therapeutic functions. When delivered to glioma cells and orthotopic glioma models, they observed that these modified exosomes could cross the BBB smoothly, and exosomes offered extraordinary outcomes for targeted imaging and treatment of GBM. SPION-mediated magnetic flow hyperthermia and Cur-mediated therapy also had a powerful anti-cancer effect when used together (102).

Interestingly, another study by Hamideh et al. showed that the administration of the exosomes carrying miR-21 into a glioma mouse model reduced the volume of the tumor (91). Moreover, Jessian L et al. also found that delivering the mesenchymal stem cell-derived exosomes to GBM loaded with anti-miR-9 increased the temozolomide chemosensitivity (80). Improving the loading capacity of an anti-cancer agent into exosomes is critical for enhancing anti-cancer medication delivery to glioma and keeping the proper drug dose in glioma tissues. Thus, several approaches, including electroporation, incubation, and chemical reagents, have been examined to increase the loading efficiency of therapeutic medicines into exosomes. Furthermore, the application of microfluidics to drug loading and delivery to cells has been researched, especially with the advancement of micro- and nanofabrication technologies (103). Recently, therapeutic loading into exosomes using microfluidics has received attention and progress from different researchers. For example, a recent study conducted by Thakur A et al. revealed that Exo-Load microfluidic device fully incorporated two BBBimpermeable anti-cancer drugs, DOX and PTX, into SF7761 stem cell-like GM-derived exosomes in the presence of saponin, a permeabilization agent, and shear stress in microfluidic channels. The sigmoid Exo-Load type outperformed the linear kind of ExoLoad in loading DOX into U251 GM-derived exosomes, indicating that Exo-Load-based drug loading into exosomes may be promising with future modification and optimization techniques. This study concluded that Exo-Load (microfluidic) device-based loading of anti-cancer drugs into exosomes and autologous uptake of EXODOXs might effectively suppress the proliferation of glioma cells (104). The facts mentioned above show that exosomes play an essential role in delivering different anti-cancer drugs, critical for managing glioma.

\subsubsection{Exosomes as Therapy Response Monitor in Glioma}

Monitoring treatment is another essentially major step in different cancer treatments. As discussed earlier, exosomes play essential roles in various vital events involved in glioma; besides, exosomes monitor various therapies' sensitivity in glioma. For example, Ailiang Zeng et al. found that exosomal miR-151a is not only a less invasive 'liquid biopsy' that may predict chemotherapy response, but miR-151a is also a promising therapeutic target for refractory GBM therapy (105). Moreover, in vivo studies verified MSC-derived exosomes' ability loaded with miR-133b to inhibit glioma tumor growth, and MSCderived exosomal miR-133b and the Wnt/ $\beta$-catenin/EZH2 pathway could act as biomarkers for monitoring and prognosis

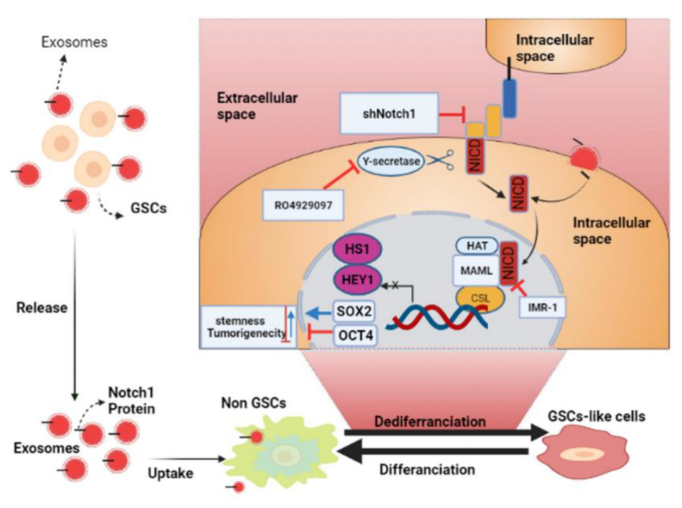

FIGURE 3 | The roles of glioma stem cell (GSC) exosomes in glioma. GSC exosomes improve the stemness and tumorigenicity of non-GSC glioma cells by conveying Notch1 protein via the Notch1 signaling pathway (BioRender.com was used to create this figure). 
TABLE 3 | Exosomes that are involved in glioma treatment.

\begin{tabular}{|c|c|c|c|c|}
\hline $\begin{array}{l}\text { Exosomal } \\
\text { content }\end{array}$ & Experimental Design & Mechanism & Outcome & References \\
\hline $\begin{array}{l}\text { miR-21 } \\
\text { sponge } \\
\text { construct }\end{array}$ & $\begin{array}{l}\text { In vitro and stereotaxically injected into a rat } \\
\text { model }\end{array}$ & $\begin{array}{l}\text { Downregulates miR-21 and } \\
\text { upregulates miR-21 target genes } \\
\text { (PDCD4 and RECK) }\end{array}$ & Reduces tumor volume & (91) \\
\hline miR-34a & $\begin{array}{l}\text { In vitro and subcutaneously injected into a rat } \\
\text { model }\end{array}$ & Downregulates MYCN & $\begin{array}{l}\text { Suppresses GBM cell growth, invasion, migration, } \\
\text { and tumorigenesis and enhances chemosensitivity } \\
\text { of the GBM cells to TMZ }\end{array}$ & (92) \\
\hline miR-375 & In vitro and a rat model & Suppresses SLC31A1 & $\begin{array}{l}\text { Promotes apoptosis and suppresses proliferation, } \\
\text { migration, and invasion }\end{array}$ & (93) \\
\hline $\begin{array}{l}\text { microRNA- } \\
7-5 p\end{array}$ & $\begin{array}{l}\text { A subcutaneous tumor model and tumor } \\
\text { metastasis model of nude mice were established } \\
\text { to validate the in vitro findings }\end{array}$ & $\begin{array}{l}\text { Inhibits the activity of the EGFR/ } \\
\text { PI3K/Akt signaling pathway }\end{array}$ & $\begin{array}{l}\text { Suppresses the proliferation, migration, invasion, } \\
\text { and microtubule formation }\end{array}$ & (94) \\
\hline $\begin{array}{l}\text { miR-29a- } \\
3 p\end{array}$ & In vitro and in vivo & Target ROBO1 & $\begin{array}{l}\text { Stops migration and VM (vasculogenic mimicry) } \\
\text { formation in glioma cells }\end{array}$ & (95) \\
\hline $\begin{array}{l}\text { miR-15a } \\
\text { and miR- } \\
92 a\end{array}$ & In vitro & $\begin{array}{l}\text { Inhibit the activity of the PI3K/ } \\
\text { AKT/mTOR signaling pathway }\end{array}$ & Inhibit cell migration and invasion of glioma cells & $(96)$ \\
\hline miR-199a & In vitro & Downregulates AGAP2 & $\begin{array}{l}\text { Suppresses tumor proliferation, invasion, and } \\
\text { migration }\end{array}$ & (88) \\
\hline $\begin{array}{l}\operatorname{miR}-454- \\
3 p\end{array}$ & In vitro & Targets ATG12 & Tumor suppressor in glioma & (83) \\
\hline $\begin{array}{l}\text { microRNA- } \\
512-5 p\end{array}$ & In vivo and in vitro & Targets JAG1 & Inhibition of glioblastoma progression & (97) \\
\hline $\begin{array}{l}\text { microRNA- } \\
133 b\end{array}$ & In vivo and in vitro & $\begin{array}{l}\text { Inhibits EZH2 and the Wnt/ } \beta \text { - } \\
\text { catenin signaling pathway }\end{array}$ & $\begin{array}{l}\text { Represses glioma cell proliferation, invasion, and } \\
\text { migration }\end{array}$ & (98) \\
\hline
\end{tabular}

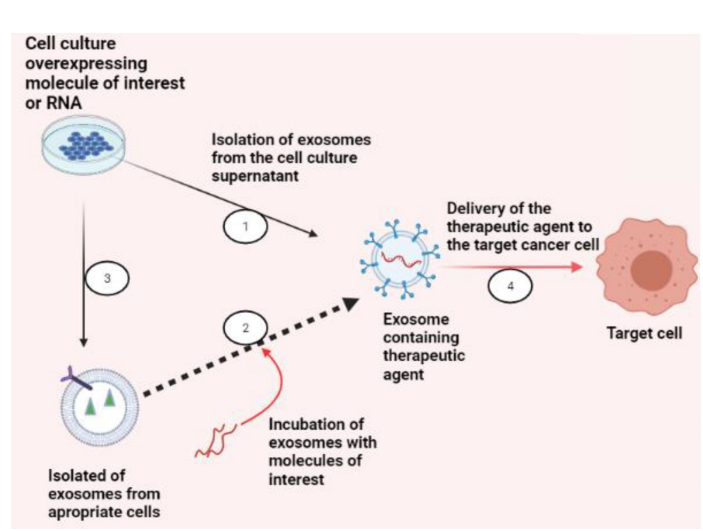

FIGURE 4 | Exosomes as a therapeutic carrier. There are two strategies to load exosomes with therapeutic cargo, like RNA species for gene silencing in targeted cancer cells or small molecule compounds of concern: (1) endogenously, by collecting exosomes from cells overexpressing the molecule of interest, or (2) exogenously, by collecting exosomes from an appropriate cell culture that produces exosomes suitable for specific targeting and then incubating or electroporating the exosomes with the molecule of interest. (3) Once the exosomes are successfully loaded, (4) exosomes can be used for their respective therapeutic applications (BioRender.com was used to create this figure).

in glioma therapy (106). Moreover, another research highlighted that exosomal miR185 and miR-205 are potential candidates to help clinically track different treatment responses in glioma (107). Recently, another study discovered that hypoxia-induced malignant GMs significantly increased MCT1 and CD147 expression, thereby facilitating calcium-dependent exosome secretion. Additionally, it was discovered that hypoxic GMderived exosomes consisted of substantially increased levels of
MCT1 and CD147, which could be quantified using non-invasive localized surface plasmon resonance and atomic force microscopy biosensors, demonstrating that they could serve as precise surrogate biomarkers for tracking metabolic reprogramming and malignant progression of glioma (108). Also, another recent study conducted by Chen $\mathrm{Xu}$ et al. used a TiO2-CTFE-AuNIs plasmonic biosensor to identify BIGH3 in exosomes produced from glioma cells to monitor the malignant 
evolution of glioma. Thus, TiO2-CTFE-AuNIs was reported to be capable of quantifying the dynamic change in exosomal $\mathrm{BIGH} 3$ in response to hypoxia and TMZ therapy. This allows the measurement of $\mathrm{BIGH} 3$ levels in parent GMs, revealing TMZ's anti-cancer impact; this makes the biosensor mentioned above show significant promise for its applicability to the identification of predictive biomarkers in GM-derived exosomes for glioma liquid biopsy (109). Even though there is a great job done about using exosomes as diagnostic and prognostic biomarkers, there is a need for deep researches to prove that exosomes can be used to monitor various therapies in glioma, which can be used in daily clinical life. This will significantly increase patients' treatment outcomes.

\subsubsection{Clinical Trials Related to Roles of Exosomes in Glioma Diagnosis and Treatment}

Clinical trials help scientists and clinicians test diagnostic and treatment tools; this applies to other cancers, including gliomas. Different clinical trials have been performed to highlight the usefulness of exosomes in the treatment and diagnosis of various cancers such as pancreatic cancer (NCT02393703) and colorectal cancer. Even though there are not too many clinical trials dealing with the potential roles of exosomes in glioma, one recruiting clinical trial aims to determine if mir-10b expression levels are a fit candidate to be a prognostic and diagnostic marker (NCT01849952); the details on the mentioned clinical trials and others are presented in Table 4. The facts mentioned above show hope that exosomes are future diagnostic and treatment tools for glioma. However, there is still a need for more clinical trials to prove the use of exosomes' roles as routine diagnostic and treatment agents for glioma.

\section{THE INVOLVEMENT OF EXOSOMES IN GLIOMA IMMUNE RESPONSES}

Exosomes play a crucial function in tumor-immune cell cooperation. Besides, exosomes secreted by tumor cells carry tumor-specific antigens that, in extraordinary circumstances, enable and suppress the immune system and promote the proliferation, invasiveness, and chemoresistance of glioma. miRNAs released from the tumor-derived exosomes can regulate the differentiation and function of the immune cells. These tumorderived exosomes have many physiopathological roles and act on a range of immune cells, including effector T cells, naturally occurring Treg cells, and natural killer cells synonymous with immune suppression and tumor progression $(110,111)$. Also, serum exosomes from GBM patients have been shown to cause M2 polarization in normal monocytes, indicating a tendency toward T-helper 2 cells (Th2). Th2 responses are considered unacceptable in tumor immunotherapy since they alleviate cytotoxic anti-tumor immune processes and help inhibit cell-mediated immunity (112). Microglia-derived exosomes often mediate essential immune responses to tumorigenesis, degeneration, and central nervous system infections (113). Antigen-dendritic cells induce T-cell activation upon incubation with genes with different expression levels (GDEs) and mediate cytotoxicity against in vitro (114). Hell Winkel and his colleagues observed that immunosuppressive phenotypes and elevated cytokine concentrations in exosomes extracted from tumors lead to decreased development of other cytokines, including interleukin 2 (IL-2) CD69, and T-cell function, obstructing the migration of lymphocytes and inhibiting the immunity of tumors (115). Exosomes derived from GBM GL26 cells reduced cytotoxic CD8+ T cells' number and function, fostering tumor growth (116). GDEs help to classify peripheral blood monocytes into alternately triggered M2 tumor-supporting macrophages (117) and regulate the development of cytokines and mononuclear migratory ability mitogen-stimulated, healthy, peripheral blood cells.

\section{THE INVOLVEMENT OF EXOSOMES IN GLIOMA TME}

A glioma's TME is incredibly diverse, comprising various cancer and non-cancer cells, such as endothelial cells, immune cells,

TABLE 4 | Examples of clinical trials done on the roles of exosomes as biomarkers or in treatment agents for glioma and other cancers.

\begin{tabular}{|c|c|c|c|}
\hline $\begin{array}{l}\text { Status of the } \\
\text { Clinical Trials }\end{array}$ & Objectives & Condition of the Disease & $\begin{array}{l}\text { Clinical Trial } \\
\text { Identifier }\end{array}$ \\
\hline Completed & $\begin{array}{l}\text { Establishment of a signature of circulating microRNA as a tool to aid } \\
\text { diagnosis of primary brain tumors in adults }\end{array}$ & Brain tumors & NCT03630861 \\
\hline Recruiting & $\begin{array}{l}\text { Assessing blood and cerebrospinal fluid metabolomic profile in glioma } \\
\text { patients }\end{array}$ & Glioma, glioblastoma multiforme & NCT03865355 \\
\hline Recruiting & $\begin{array}{l}\text { Assessing the ability of exosomes in treating participants with metastatic } \\
\text { pancreatic cancer with KrasG12D mutation }\end{array}$ & $\begin{array}{l}\text { KRAS NP_004976.2: p.G12D, } \\
\text { Metastatic pancreatic, adenocarcinoma, pancreatic } \\
\text { ductal adenocarcinoma, stage IV pancreatic }\end{array}$ & NCT03608631 \\
\hline Recruiting & $\begin{array}{l}\text { To characterize exosomal biomarker levels in patients with locally advanced } \\
\text { rectal cancer undergoing neoadjuvant chemoradiation therapy }\end{array}$ & Rectal cancer & NCT03874559 \\
\hline Recruiting & Identification of new diagnostic protein markers for colorectal cancer & Colorectal cancer & NCT04394572 \\
\hline
\end{tabular}


glioma stem-like cells, and atrocities' non-cellular elements, including the extracellular matrix $(118,119)$. The tumor microenvironment is progressively recognized as a strong promoter of glioma advancement, playing a leading role in controlling tumor growth (120). Therefore, exosomes have been viewed as a necessary two-way contact between the tumor and the tumor microenvironment (121). Different studies have been conducted to reveal the linkage between exosomes and the glioma's microenvironment. For instance, a study reported that the miR-340-5p-macrophage virtuous cycle changed GBM development and TM (122). Over the last few years, studies suggested EVs produced by GBM cells interact with the activation of this tumor-supporting Tumor-Associated Macrophage (TAM) phenotype modulation. For example, a study showed that EVs derived from GBMs' primary cultures had manipulated the TAM phenotype in vitro, converting it into an M2-like anti-inflammatory phenotype that resembles a tumor-supporting phenotype found in patients. Phenotypic changes included changed expression of a wide range of cell surfaces and enhanced release of cytokines such as interleukin-6 (IL-6) and vascular endothelial growth factor. In addition, GBMderived exosomes mediated and enhanced macrophages' phagocytic activity, enhancing the extracellular matrix's deterioration and promoting the migration of tumor cells (117). It has been shown that exosomes, isolated from GBM cell line U87 and the GSCs, primarily target monocytes to cause the restructuring of the actin cytoskeleton and immunosuppressive phenotype $\mathrm{M} 2$, with the release of cytokines like MCP-3 and CXCL1 (123). Exosomes are among the many ways GBM cells interact with the tumor microenvironment to their advantage. Based on the researches mentioned above, it is very clear that exosomes play essential roles in glioma TME. However, different advanced studies are needed to deeply highlight the extended functions of exosomes in gliomas' tumor microenvironment.

\section{LIMITATIONS AND FUTURE PROSPECTIVE}

Exosome research in gliomas is a new and fast-developing area. It is clear that exosomes can be used to create therapeutic strategies to prevent and treat glioma growth and development. Nevertheless, many issues remain unresolved, such as the lack of consistency and consistency in exosome detection, isolation, and purification methods. Table 5 summarizes the benefits and drawbacks of exosome isolation techniques. Second, the approach by which exosomes are taken up by recipient cells is unknown. Additionally, brain tissue collection is more complicated. Additional researches are necessary to thoroughly understand the pathophysiology of exosomes in gliomas and show exosomes' involvement in the illness.

\section{CONCLUSIONS}

Exosomes are a novel mode of cell communication that facilitates communication between parent and target cells and changes the tumor microenvironment, promoting cancer progression.

TABLE 5 | Exosome's isolation methods, advantages, and disadvantages.

\begin{tabular}{|c|c|c|c|c|}
\hline Methods & Theory & Advantages & Disadvantages & Reference \\
\hline $\begin{array}{l}\text { Ultracentrifugation } \\
\text { techniques }\end{array}$ & $\begin{array}{l}\text { The required components } \\
\text { are obtained according to } \\
\text { the size and density } \\
\text { differences for each } \\
\text { element in the sample. }\end{array}$ & $\begin{array}{l}\text { There is no need to mark the outer cut } \\
\text { body to avoid cross-contaminations. }\end{array}$ & $\begin{array}{l}\text { High cost, time-consuming, structural failure, aggregation, } \\
\text { and lipoprotein separation is not conducted to downstream } \\
\text { analysis }\end{array}$ & $(124,125)$ \\
\hline $\begin{array}{l}\text { Density gradient } \\
\text { centrifugation }\end{array}$ & $\begin{array}{l}\text { Usually used in } \\
\text { combination with the } \\
\text { overspeed centrifuge } \\
\text { method }\end{array}$ & Improves the purity of exosomes & $\begin{array}{l}\text { The high viscosity of sucrose solution will reduce the settling } \\
\text { velocity of exosomes and lead to more time consumed. }\end{array}$ & $(126,127)$ \\
\hline $\begin{array}{l}\text { Size-based } \\
\text { isolation } \\
\text { techniques }\end{array}$ & $\begin{array}{l}\text { Based on the size } \\
\text { differences between } \\
\text { exosomes and other } \\
\text { components of a biological } \\
\text { sample }\end{array}$ & $\begin{array}{l}\text { Fast, simple, low-cost, and separated } \\
\text { exosomes have complete structure and } \\
\text { uniform size. Their biological } \\
\text { characteristics will not be significantly } \\
\text { affected. }\end{array}$ & $\begin{array}{l}\text { Other particles of similar size are difficult to separate, } \\
\text { resulting in reduced purity. }\end{array}$ & (128) \\
\hline Ultrafiltration & $\begin{array}{l}\text { Ultrafiltration membranes } \\
\text { with different molecular } \\
\text { weight cutoffs were used to } \\
\text { separate the samples } \\
\text { selectively. }\end{array}$ & $\begin{array}{l}\text { The sample cost is low, the } \\
\text { concentration efficiency is high, and the } \\
\text { activity of the exosomes is not affected. }\end{array}$ & $\begin{array}{l}\text { Low purity and poor binding of the exosomes to the } \\
\text { ultrafiltration membrane resulted in a low recovery rate. }\end{array}$ & (129) \\
\hline $\begin{array}{l}\text { Immunoaffinity } \\
\text { chromatography }\end{array}$ & $\begin{array}{l}\text { The specificity of antibodies } \\
\text { and the ligand is combined } \\
\text { to separate the required } \\
\text { exosomes from } \\
\text { heterogeneous mixtures. }\end{array}$ & $\begin{array}{l}\text { The sample size needed is small. It can } \\
\text { be used to qualitatively and } \\
\text { quantitatively detect exosomes. This } \\
\text { method has strong specificity, high } \\
\text { sensitivity, high purity, and high yield. }\end{array}$ & $\begin{array}{l}\text { The preservation condition of the exosomes obtained by this } \\
\text { method is harsh. It is not suitable for large-scale separation } \\
\text { of the exosomes. The non-specific interference adsorption of } \\
\text { matrix produces interfering proteins, which limits the broad } \\
\text { application of this method. }\end{array}$ & (130) \\
\hline
\end{tabular}


Recent research has highlighted their involvement in the pathways through which gliomas develop, infiltrate surrounding tissue, create resistance to therapy, and spread throughout the body. Continuously studying exosomes will alter and complement current understandings of carcinogenesis and development, thus contributing to a complete understanding of tumor-related molecular processes. It will also help discover efficient biomarkers and targeted tumor therapies using exosomes, improving efficacy and medication usage for glioma. However, more deep studies are needed that incorporate new advanced technologies such as machine learning, scRNA-seq, and high-throughput screening to enhance the characterization of exosomal drugs as carriers to get more reliable therapeutic and diagnostic results. In addition, more clinical trials are needed to prove exosomes' usefulness as future daily therapeutic agents and biomarker tools for gliomas and other types of cancers.

\section{REFERENCES}

1. Koshy M, Villano JL, Dolecek TA, Howard A, Mahmood U, Chmura SJ, et al. Improved Survival Time Trends for Glioblastoma Using the SEER 17 Population-Based Registries. J Neurooncol (2012) 107(1):207-12. doi: 10.1007/s11060-011-0738-7

2. Ostrom QT, Gittleman H, Liao P, Vecchione-Koval T, Wolinsky Y, Kruchko C, et al. CBTRUS Statistical Report: Primary Brain and Other Central Nervous System Tumors Diagnosed in the United States in 2010-2014. Neuro-Oncology (2017) 19:v1-v88. doi: 10.1093/neuonc/nox158

3. Wen PY, Kesari S. Malignant Gliomas in Adults. N Eng J Med (2008) 359 (5):492-507. doi: 10.1056/NEJMra0708126

4. Silantyev AS, Falzone L, Libra M, Gurina OI, Kardashova KS, Nikolouzakis TK, et al. Current and Future Trends on Diagnosis and Prognosis of Glioblastoma: From Molecular Biology to Proteomics. Cells (2019) 8:863. doi: $10.3390 /$ cells 8080863

5. Stupp C, Brada DT. Glioblastoma Multiforme: Pathogenesis and Treatment. Pharmacology \& Therapeutics (2015) 152:63-82. doi: 10.1016/ j.pharmthera.2015.05.005

6. Stupp R, Brada M, van den Bent MJ, Tonn JC, Pentheroudakis G. HighGrade Glioma: ESMO Clinical Practice Guidelines for Diagnosis, Treatment and Follow-Up. Ann Oncol (2014) 25:iii93-101. doi: 10.1093/annonc/ mdu050

7. Stupp R, Mason WP, Van Den Bent MJ, Weller M, Fisher B, Taphoorn MJB, et al. Et Al: Radiotherapy Plus Concomitant and Adjuvant Temozolomide for Glioblastoma. New Engl J Med (2005) 27:15-6. doi: 10.1097/ 01.COT.0000289242.47980.f9

8. Lim M, Xia Y, Bettegowda C, Weller M. Current State of Immunotherapy for Glioblastoma. Nat Rev Clin Oncol (2018) 15:422-442. doi: 10.1038/ s41571-018-0003-5

9. Wang J, Bettegowda C. Applications of DNA-Based Liquid Biopsy for Central Nervous System Neoplasms. J Mol Diagn (2017) 19:24-34. doi: 10.1016/j.jmoldx.2016.08.007

10. Best MG, Sol N, Zijl S, Reijneveld JC, Wesseling P, Wurdinger T. Liquid Biopsies in Patients With Diffuse Glioma. Acta Neuropathol (2015) 129:84965.

11. Posti JP, Bori M, Kauko T, Sankinen M, Nordberg J, Rahi M, et al. Presenting Symptoms of Glioma in Adults. Acta Neurol Scand (2015) 129:849-865. doi: 10.1111/ane. 12285

12. Edgar JR. Q\&A: What are Exosomes, Exactly? BMC Biol (2016) 14(1):46. doi: 10.1186/s12915-016-0268-Z

13. Kalluri R, LeBleu VS. The Biology, Function, and Biomedical Applications of Exosomes. Science (2020) 367(6478):eaau6977. doi: 10.1126/science.aau6977

\section{AUTHOR CONTRIBUTIONS}

XiaobW designed and drafted the manuscript. XingbW, JW, YH, FL, XinW, LY, and ZL discussed and revised the manuscript. All authors read and approved the final manuscript.

\section{FUNDING}

This study was supported by the Clinical Medicine Science and Technology Innovation Project of JINAN (No. 202019020).

\section{ACKNOWLEDGMENTS}

The figures have been created by BioRender.com.

14. Tkach M, Théry C. Communication by Extracellular Vesicles: Where We Are and Where We Need to Go. Cell (2016) 164:1226-32. doi: 10.1016/ j.cell.2016.01.043

15. Thakur A, Sidu RK, Gaurav I, Sweta K, Chakraborty P, Thakur S. 17 Modified Biopolymer-Based Systems for Drug Delivery to the Brain. In: $\mathrm{H}$ Bera, B Layek, J Singh, editors. Tailor-Made and Functionalized Biopolymer Systems. Cambridge, England: Woodhead Publishing (2021). p. 571-611.

16. Schneider A, Simons M. Exosomes: Vesicular Carriers for Intercellular Communication in Neurodegenerative Disorders. Cell Tissue Res (2013) 352:33-47. doi: 10.1007/s00441-012-1428-2

17. Gourlay J, Morokoff AP, Luwor RB, Zhu HJ, Kaye AH, Stylli SS. The Emergent Role of Exosomes in Glioma. J Clin Neurosci (2017) 35:13-23. doi: 10.1016/j.jocn.2016.09.021

18. Sun Z, Shi K, Yang S, Liu J, Zhou Q, Wang G, et al. Effect of Exosomal miRNA on Cancer Biology and Clinical Applications. Mol Cancer (2018) 17 (1):1-19. doi: 10.1186/s12943-018-0897-7

19. Gurunathan S, Kang MH, Kim JH. A Comprehensive Review on Factors Influences Biogenesis, Functions, Therapeutic and Clinical Implications of Exosomes. Int J Nanomed (2021) 16:1281-312. doi: 10.2147/IJN.S291956

20. Aqil F, Munagala R, Jeyabalan J, Agrawal AK, Gupta R. Exosomes for the Enhanced Tissue Bioavailability and Efficacy of Curcumin. AAPS J (2017) 19 (6):1691-702. doi: 10.1208/s12248-017-0154-9

21. Thakur A, Parra DC, Motallebnejad P, Brocchi M, Chen HJ. Exosomes: Small Vesicles With Big Roles in Cancer, Vaccine Development, and Therapeutics. Bioact Mater (2021). doi: 10.1016/j.bioactmat.2021.08.029

22. Gaurav I, Thakur A, Iyaswamy A, Wang X, Chen X, Yang Z. Factors Affecting Extracellular Vesicles Based Drug Delivery Systems. Molecules (2021) 26(6):1544. doi: 10.3390/molecules26061544

23. Zhang Y, Liu Y, Liu H, Tang WH. Exosomes: Biogenesis, Biologic Function and Clinical Potential. Cell Biosci (2019) 9(1):19. doi: 10.1186/s13578-019-0282-2

24. Yue B, Yang H, Wang J, Ru W, Wu J, Huang Y, et al. Exosome Biogenesis, Secretion and Function of Exosomal miRNAs in Skeletal Muscle Myogenesis. Cell Prolif (2020) 53(7):e12857. doi: 10.1111/cpr.12857

25. Patil AA, Rhee WJ. Exosomes: Biogenesis, Composition, Functions, and Their Role in Pre-Metastatic Niche Formation. Biotechnol Bioprocess Eng (2019) 24(5):689-701. doi: 10.1007/s12257-019-0170-y

26. Juan T, Fürthauer M. Biogenesis and Function of ESCRT-Dependent Extracellular Vesicles. Semin Cell Dev Biol (2018) 74:66-77. doi: 10.1016/ j.semcdb.2017.08.022

27. Burkova EE, Sedykh SE, Nevinsky GA. Human Placenta Exosomes: Biogenesis. Isolation Compos Prospects Use Diagn (2021) 22(4):2158. doi: $10.3390 /$ ijms 22042158 
28. Ju Y, Bai H, Ren L, Zhang L. The Role of Exosome and the ESCRT Pathway on Enveloped Virus Infection. Int J Mol Sci (2021) 22(16):9060. doi: 10.3390/ ijms 22169060

29. Frankel EB, Audhya A. ESCRT-Dependent Cargo Sorting at Multivesicular Endosomes. Semin Cell Dev Biol (2018) 74:4-10. doi: 10.1016/ j.semcdb.2017.08.020

30. O'Brien K, Breyne K, Ughetto S, Laurent LC, Breakefield XO. RNA Delivery by Extracellular Vesicles in Mammalian Cells and its Applications. Nat Rev Mol Cell Biol (2020) 21(10):585-606. doi: 10.1038/s41580-020-0251-y

31. Svensson KJ, Christianson HC, Wittrup A, Bourseau-Guilmain E, Lindqvist E, Svensson LM, et al. Exosome Uptake Depends on ERK1/2-Heat Shock Protein 27 Signaling and Lipid Raft-Mediated Endocytosis Negatively Regulated by Caveolin-1. J Biol Chem (2013) 288(24):17713-24. doi: 10.1074/jbc.M112.445403

32. Skotland T, Hessvik NP, Sandvig K, Llorente A. Exosomal Lipid Composition and the Role of Ether Lipids and Phosphoinositides in Exosome Biology. J Lipid Res (2019) 60(1):9-18. doi: 10.1194/jlr.R084343

33. Elsherbini A, Bieberich E. Ceramide and Exosomes: A Novel Target in Cancer Biology and Therapy. Adv Cancer Res (2018) 140:121-54. doi: 10.1016/bs.acr.2018.05.004

34. Li J, Chen X, Zhu L, Lao Z, Zhou T, Zang L, et al. Et Al: SOX9 Is a Critical Regulator of TSPAN8-Mediated Metastasis in Pancreatic Cancer. Oncogene (2021) 40(30):4884-93. doi: 10.1038/s41388-021-01864-9

35. Hessvik NP, Llorente A. Current Knowledge on Exosome Biogenesis and Release. Cell Mol Life Sci CMLS (2018) 75(2):193-208. doi: 10.1007/s00018017-2595-9

36. Daßler-Plenker J, Küttner V, Egeblad M. Communication in Tiny Packages: Exosomes as Means of Tumor-Stroma Communication. Biochim Biophys Acta Rev Cancer (2020) 1873(2):188340. doi: 10.1016/ j.bbcan.2020.188340

37. Osaki M, Okada F. Exosomes and Their Role in Cancer Progression. Yonago Acta Med (2019) 62(2):182-90. doi: 10.33160/yam.2019.06.002

38. Von Schulze A, Deng F. A Review on Exosome-Based Cancer Therapy. J Cancer Metastasis Treat (2020) 6:42. doi: 10.20517/2394-4722.2020.79

39. Whitehead CA, Kaye AH, Drummond KJ, Widodo SS, Mantamadiotis T, Vella LJ, et al. Extracellular Vesicles and Their Role in Glioblastoma. Crit Rev Clin Lab Sci (2019) 57:1-26. doi: 10.1080/10408363.2019.1700208

40. Basu B, Ghosh MK. Extracellular Vesicles in Glioma: From Diagnosis to Therapy. BioEssays News Rev mol Cell Dev Biol (2019) 41(7):e1800245. doi: 10.1002/bies.201800245

41. Cheng J, Meng J, Zhu L, Peng Y. Exosomal Noncoding RNAs in Glioma: Biological Functions and Potential Clinical Applications. Mol Cancer (2020) 19(1):66. doi: 10.1186/s12943-020-01189-3

42. Lang HL, Hu GW, Zhang B, Kuang W, Chen Y, Wu L, et al. Glioma Cells Enhance Angiogenesis and Inhibit Endothelial Cell Apoptosis Through the Release of Exosomes That Contain Long non-Coding RNA Ccat2. Oncol Rep (2017) 38(2):785-98. doi: 10.3892/or.2017.5742

43. Guo H, Wu L, Yang Q, Ye M, Zhu X. Functional Linc-POU3F3 is Overexpressed and Contributes to Tumorigenesis in Glioma. Gene (2015) 554(1):114-9. doi: 10.1016/j.gene.2014.10.038

44. Kucharzewska P, Christianson HC, Welch JE, Svensson KJ, Fredlund E, Ringner M, et al. Exosomes Reflect the Hypoxic Status of Glioma Cells and Mediate Hypoxia-Dependent Activation of Vascular Cells During Tumor Development. Proc Natl Acad Sci USA (2013) 110(18):7312-7. doi: 10.1073/ pnas. 1220998110

45. Sun X, Ma X, Wang J, Zhao Y, Wang Y, Bihl JC, et al. Glioma Stem CellsDerived Exosomes Promote the Angiogenic Ability of Endothelial Cells Through miR-21/VEGF Signal. Oncotarget (2017) 8(22):36137-48. doi: 10.18632/oncotarget.16661

46. Cai Q, Zhu A, Gong L. Exosomes of Glioma Cells Deliver miR-148a to Promote Proliferation and Metastasis of Glioblastoma via Targeting CADM1. Bull Cancer (2018) 105(7-8):643-51. doi: 10.1016/j.bulcan. 2018.05.003

47. Kamran MZ, Patil P, Gude RP. Role of STAT3 in Cancer Metastasis and Translational Advances. BioMed Res International (2013) 2013:1-15. doi: $10.1155 / 2013 / 421821$

48. Ma Z, Cui X, Lu L, Chen G, Yang Y, Hu Y, et al. Exosomes From Glioma Cells Induce a Tumor-Like Phenotype in Mesenchymal Stem Cells by
Activating Glycolysis. Stem Cell Res Ther (2019) 10(1):60. doi: 10.1186/ s13287-019-1149-5

49. Gu Q, Chen X, Zhou L, Liu X. Exosome EpCAM Promotes the Metastasis of Glioma by Targeting the CD44 Signaling Molecule on the Surface of Glioma Cells. Adv Clin Exp Med Off Organ Wroclaw Med Univ (2020) 29(11):127782. doi: $10.17219 /$ acem/126051

50. Pace KR, Dutt R, Galileo DS. Exosomal L1CAM Stimulates Glioblastoma Cell Motility, Proliferation, and Invasiveness. Int J Mol Sci (2019) 20 (16):3982. doi: 10.3390/ijms20163982

51. Peng G, Yang C, Liu Y, Shen C. Mir-25-3p Promotes Glioma Cell Proliferation and Migration by Targeting FBXW7 and DKK3. Exp Ther Med (2019) 18:769-78. doi: 10.3892/etm.2019.7583

52. Lu GF, You CY, Chen YS, Jiang H, Zheng X, Tang WW, et al. MicroRNA671-3p Promotes Proliferation and Migration of Glioma Cells via Targeting CKAP4. OncoTargets Ther (2018) 11:6217-26. doi: 10.2147/OTT.S177325

53. Chen Y, Deng X, Chen W, Shi P, Lian M, Wang H, et al. Silencing of microRNA-708 Promotes Cell Growth and Epithelial-to-Mesenchymal Transition by Activating the SPHK2/AKT/ $\beta$-Catenin Pathway in Glioma. Cell Death Dis (2019) 10(6):448. doi: 10.1038/s41419-019-1671-5

54. Ma C, Wei F, Xia H, Liu H, Dong X, Zhang Y, et al. MicroRNA-10b Mediates TGF- $\beta 1$-Regulated Glioblastoma Proliferation, Migration and EpithelialMesenchymal Transition. Int J Oncol (2017) 50(5):1739-48. doi: 10.3892/ ijo.2017.3947

55. Riches A, Campbell E, Borger E, Powis S. Regulation of Exosome Release From Mammary Epithelial and Breast Cancer Cells - a New Regulatory Pathway. Eur J Cancer (2014) 50(5):1025-34. doi: 10.1016/j.ejca.2013.12.019

56. Buruiană A, Florian ȘI, Florian AI, Timiș TL, Mihu CM, Miclăuș M, et al The Roles of miRNA in Glioblastoma Tumor Cell Communication: Diplomatic and Aggressive Negotiations. Int J Mol Sci (2020) 21(6):1950. doi: $10.3390 /$ ijms21061950

57. Figueroa J, Phillips LM, Shahar T, Hossain A, Gumin J, Kim H, et al. Exosomes From Glioma-Associated Mesenchymal Stem Cells Increase the Tumorigenicity of Glioma Stem-Like Cells via Transfer of miR-1587. Cancer Res (2017) 77(21):5808-19. doi: 10.1158/0008-5472.CAN-16-2524

58. Wang M, Zhao Y, Yu ZY, Zhang RD, Li SA, Zhang P, et al. Glioma Exosomal microRNA-148a-3p Promotes Tumor Angiogenesis Through Activating the EGFR/MAPK Signaling Pathway via Inhibiting ERRFI1. Cancer Cell Int (2020) 20:518. doi: 10.1186/s12935-020-01566-4

59. Chen G, Chen Z, Zhao H. MicroRNA-155-3p Promotes Glioma Progression and Temozolomide Resistance by Targeting Six1. J Cell Mol Med (2020) 24 (9):5363-74. doi: 10.1111/jcmm.15192

60. Lu GF, Geng F, Xiao Z, Chen YS, Han Y, You CY, et al. MicroRNA-6807-3p Promotes the Tumorigenesis of Glioma by Targeting Downstream DACH1. Brain Res (2019) 1708:47-57. doi: 10.1016/j.brainres.2018.12.008

61. Hu LS, Hawkins-Daarud A, Wang L, Li J, Swanson KR. Imaging of Intratumoral Heterogeneity in High-Grade Glioma. Cancer Lett (2020) 477:97-106. doi: 10.1016/j.canlet.2020.02.025

62. Bălașa A, Șerban G, Chinezu R, Hurghiș C, Tămaș F, Manu D. The Involvement of Exosomes in Glioblastoma Development, Diagnosis, Prognosis, and Treatment. Brain Sci (2020) 10(8):553. doi: 10.3390/ brainsci10080553

63. Yang L, Ma Y, Xin Y, Han R, Li R, Hao X. Role of the microRNA 181 Family in Glioma Development. Mol Med Rep (2018) 17:322-9. doi: 10.3892/ mmr.2017.7895

64. Shi Z, Chen Q, Li C, Wang L, Qian X, Jiang C, et al. MiR-124 Governs Glioma Growth and Angiogenesis and Enhances Chemosensitivity by Targeting R-Ras and N-Ras. Neuro-Oncology (2014) 16:1341-53. doi 10.1093/neuonc/nou084

65. Lan F, Qing Q, Pan Q, Hu M, Yu H, Yue X. Serum Exosomal miR-301a as a Potential Diagnostic and Prognostic Biomarker for Human Glioma. Cell Oncol (2018) 41:25-33. doi: 10.1007/s13402-017-0355-3

66. Yue X, Lan F, Hu M, Pan Q, Wang Q, Wang J. Downregulation of Serum microRNA-205 as a Potential Diagnostic and Prognostic Biomarker for Human Glioma. J Neurosurg (2016) 124:122-8. doi: 10.3171/ 2015.1.JNS141577

67. Zhang R, Pang B, Xin T, Guo H, Xing Y, Xu S, et al. Plasma miR-221/222 Family as Novel Descriptive and Prognostic Biomarkers for Glioma. Mo Neurobiol (2016) 53(3):1452-60. doi: 10.1007/s12035-014-9079-9 
68. Liang RF, Li M, Yang Y, Wang X, Mao Q, Liu YH. Circulating miR-128 as a Potential Diagnostic Biomarker for Glioma. Clin Neuro Neurosurg (2017) 160:88-91. doi: 10.1016/j.clineuro.2017.06.020

69. Santangelo A, Imbrucè P, Gardenghi B, Belli L, Agushi R, Tamanini A, et al. A microRNA Signature From Serum Exosomes of Patients With Glioma as Complementary Diagnostic Biomarker. J Neuro-Oncol (2018) 136:51-62. doi: 10.1007/s11060-017-2639-x

70. Manterola L, Guruceaga E, Pérez-Larraya JG, González-Huarriz M, Jauregui P, Tejada S, et al. A Small Noncoding RNA Signature Found in Exosomes of GBM Patient Serum as a Diagnostic Tool. Neuro-Oncology (2014) 16:52027. doi: $10.1093 /$ neuonc/not 218

71. Ding C, Yi X, Wu X, Bu X, Wang D, Wu Z, et al. Exosome-Mediated Transfer of circRNA CircNFIX Enhances Temozolomide Resistance in Glioma. Cancer Lett (2020) 479:1-12. doi: 10.1016/j.canlet.2020.03.002

72. Tan SK, Pastori C, Penas C, Komotar RJ, Ivan ME, Wahlestedt C, et al. Serum Long Noncoding RNA HOTAIR as a Novel Diagnostic and Prognostic Biomarker in Glioblastoma Multiforme. Mol Cancer (2018) 17 (1):74. doi: 10.1186/s12943-018-0822-0

73. Indira Chandran V, Welinder C, Månsson A-S, Offer S, Freyhult E, Pernemalm M, et al. Ultrasensitive Immunoprofiling of Plasma Extracellular Vesicles Identifies Syndecan-1 as a Potential Tool for Minimally Invasive Diagnosis of Glioma. Clin Cancer Res (2019) 25 (10):3115-27. doi: 10.1158/1078-0432.CCR-18-2946

74. An Z, Aksoy O, Zheng T, Fan QW, Weiss WA. Epidermal Growth Factor Receptor and EGFRvIII in Glioblastoma: Signaling Pathways and Targeted Therapies. Oncogene (2018) 37(12):1561-75. doi: 10.1038/s41388-017-0045-7

75. Manda SV, Kataria Y, Tatireddy BR, Ramakrishnan B, Ratnam BG, Lath R, et al. Exosomes as a Biomarker Platform for Detecting Epidermal Growth Factor Receptor-Positive High-Grade Gliomas. J Neurosur (2018) 128 (4):1091-101. doi: 10.3171/2016.11.JNS161187

76. Hapuarachchige S, Artemov D. Theranostic Pretargeting Drug Delivery and Imaging Platforms in Cancer Precision Medicine. Frontiers in Oncology (2020) 10(1131):1131. doi: 10.3389/fonc.2020.01131

77. Al-Sowayan BS, Al-Shareeda AT. Nanogenomics and Artificial Intelligence: A Dynamic Duo for the Fight Against Breast Cancer. Frontiers in Molecular Biosciences (2021) 8(219):219. doi: 10.3389/fmolb.2021.651588

78. Ko J, Bhagwat N, Yee SS, Ortiz N, Sahmoud A, Black T, et al. Combining Machine Learning and Nanofluidic Technology To Diagnose Pancreatic Cancer Using Exosomes. ACS Nano (2017) 11(11):11182-93. doi: 10.1021/ acsnano.7b05503

79. Katakowski M, Buller B, Zheng X, Lu Y, Rogers T, Osobamiro O, et al. Exosomes From Marrow Stromal Cells Expressing miR-146b Inhibit Glioma Growth. Cancer Lett (2013) 335:201-04. doi: 10.1016/j.canlet.2013.02.019

80. Munoz JL, Bliss SA, Greco SJ, Ramkissoon SH, Ligon KL, Rameshwar P. Delivery of Functional Anti-miR-9 by Mesenchymal Stem Cell-Derived Exosomes to Glioblastoma Multiforme Cells Conferred Chemosensitivity. Mol Ther Nucleic Acids (2013) 2(10):e126. doi: 10.1038/mtna.2013.60

81. Zhang Z, Yin J, Lu C, Wei Y, Zeng A, You Y. Exosomal Transfer of Long non-Coding RNA SBF2-AS1 Enhances Chemoresistance to Temozolomide in Glioblastoma. J Exp Clin Cancer Res (2019) 38(1):166. doi: 10.1186/ s13046-019-1139-6

82. Yin J, Zeng A, Zhang Z, Shi Z, Yan W, You Y. Exosomal Transfer of miR1238 Contributes to Temozolomide-Resistance in Glioblastoma. EBioMedicine (2019) 42:238-51. doi: 10.1016/j.ebiom.2019.03.016

83. Shao N, Xue L, Wang R, Luo K, Zhi F, Lan Q. miR-454-3p Is an Exosomal Biomarker and Functions as a Tumor Suppressor in Glioma. Mol Cancer Ther (2019) 18(2):459. doi: 10.1158/1535-7163.MCT-18-0725

84. Nan Y, Han L, Zhang A, Wang G, Jia Z, Yang Y, et al. MiRNA-451 Plays a Role as Tumor Suppressor in Human Glioma Cells. Brain Res (2010) 1359:14-21. doi: 10.1016/j.brainres.2010.08.074

85. Gabriely G, Yi M, Narayan RS, Niers JM, Wurdinger T, Imitola J, et al. Human Glioma Growth is Controlled by microRNA-10b. Cancer Res (2011) 71:3563-72. doi: 10.1158/0008-5472.CAN-10-3568

86. Yunqing L, Guessous F, Ying Z, DiPierro C, Kefas B, Johnson E, et al. MicroRNA-34a Inhibits Glioblastoma Growth by Targeting Multiple Oncogenes. Cancer Res (2009) 69:7569-76. doi: 10.1158/0008-5472.can09-0529
87. Mei J, Bachoo R, Zhang CL. MicroRNA-146a Inhibits Glioma Development by Targeting Notch1. Mol Cell Biol (2011) 31:3584-92. doi: 10.1128/ MCB.05821-11

88. Yu L, Gui S, Liu Y, Qiu X, Zhang G, Zhang X, et al. Exosomes Derived From microRNA-199a-Overexpressing Mesenchymal Stem Cells Inhibit Glioma Progression by Down-Regulating AGAP2. Aging (Albany NY) (2019) 11 (15):5300-18. doi: 10.18632/aging.102092

89. Qian M, Wang S, Guo X, Wang J, Zhang Z, Qiu W, et al. Hypoxic Glioma-Derived Exosomes Deliver microRNA-1246 to Induce M2 Macrophage Polarization by Targeting TERF2IP via the STAT3 and NF-kb Pathways. Oncogene (2020) 39:428-42. doi: 10.1038/s41388-0190996-y

90. Sun Z, Wang L, Zhou Y, Dong L, Ma W, Lv L, et al. Glioblastoma Stem CellDerived Exosomes Enhance Stemness and Tumorigenicity of Glioma Cells by Transferring Notch1 Protein. Cell Mol Neurobiol (2020) 40(5):767-84. doi: 10.1007/s10571-019-00771-8

91. Monfared H, Jahangard Y, Nikkhah M, Mirnajafi-Zadeh J, Mowla SJ. Potential Therapeutic Effects of Exosomes Packed With a miR-21-Sponge Construct in a Rat Model of Glioblastoma. Front Oncol (2019) 9:782. doi: 10.3389/fonc.2019.00782

92. Wang B, Wu ZH, Lou PY, Chai C, Han SY, Ning JF, et al. Human Bone Marrow-Derived Mesenchymal Stem Cell-Secreted Exosomes Overexpressing microRNA-34a Ameliorate Glioblastoma Development via Down-Regulating MYCN. Cell Oncol (Dordrecht) (2019) 42(6):783-99. doi 10.1007/s13402-019-00461-Z

93. Deng SZ, Lai MF, Li YP, Xu CH, Zhang HR, Kuang JG. Human Marrow Stromal Cells Secrete microRNA-375-Containing Exosomes to Regulate Glioma Progression. Cancer Gene Ther (2020) 27(3-4):203-15. doi: 10.1038/s41417-019-0079-9

94. Wang H, Feng J, Ao F, Tang Y, Xu P, Wang M, et al. Tumor-Derived Exosomal microRNA-7-5p Enhanced by Verbascoside Inhibits Biologica Behaviors of Glioblastoma In Vitro and In Vivo. Mol Ther - Oncolytics (2021) 20:569-82. doi: 10.1016/j.omto.2020.12.006

95. Zhang Z, Guo X, Guo X, Yu R, Qian M, Wang S, et al. MicroRNA-29a-3p Delivery via Exosomes Derived From Engineered Human Mesenchymal Stem Cells Exerts Tumour Suppressive Effects by Inhibiting Migration and Vasculogenic Mimicry in Glioma. Aging (2021) 13(4):5055-68. doi: 10.18632/aging.202424

96. Yao J, Wang Z, Cheng Y, Ma C, Zhong Y, Xiao Y, et al. M2 MacrophageDerived Exosomal microRNAs Inhibit Cell Migration and Invasion in Gliomas Through PI3K/AKT/mTOR Signaling Pathway. J Trans Med (2021) 19(1):99. doi: 10.1186/s12967-021-02920-4

97. Yan T, Wu M, Lv S, Hu Q, Xu W, Zeng A, et al. Exosomes Derived From microRNA-512-5p-Transfected Bone Mesenchymal Stem Cells Inhibit Glioblastoma Progression by Targeting JAG1. Aging (2021) 13(7):9911-26. doi: 10.18632/aging.202747

98. Xu H, Zhao G, Zhang Y, Jiang H, Wang W, Zhao D, et al. Mesenchymal Stem Cell-Derived Exosomal microRNA-133b Suppresses Glioma Progression via Wnt/ $\beta$-Catenin Signaling Pathway by Targeting EZH2. Stem Cell Res Ther (2019) 10(1):381-1. doi: 10.1186/s13287-019-1446-Z

99. Kim H, Kim EH, Kwak G, Chi SG, Kim SH, Yang Y. Exosomes: Cell-Derived Nanoplatforms for the Delivery of Cancer Therapeutics. Int J Mol Sci (2020) 22(1):12. doi: 10.3390/ijms22010014

100. Ha D, Yang N, Nadithe V. Exosomes as Therapeutic Drug Carriers and Delivery Vehicles Across Biological Membranes: Current Perspectives and Future Challenges. Acta Pharm Sin B (2016) 6(4):287-96. doi: 10.1016/ j.apsb.2016.02.001

101. Dai J, Su Y, Zhong S, Cong L, Liu B, Yang J, et al. Exosomes: Key Players in Cancer and Potential Therapeutic Strategy. Signal Transduction Targeted Ther (2020) 5(1):145. doi: 10.1038/s41392-020-00261-0

102. Jia G, Han Y, An Y, Ding Y, He C, Wang X, et al. NRP-1 Targeted and CargoLoaded Exosomes Facilitate Simultaneous Imaging and Therapy of Glioma In Vitro and In Vivo. Biomaterials (2018) 178:302-16. doi: 10.1016/ j.biomaterials.2018.06.029

103. Damiati S, Kompella UB, Damiati SA, Kodzius R. Microfluidic Devices for Drug Delivery Systems and Drug Screening. Genes (Basel) (2018) 9(2):103. doi: 10.3390/genes9020103 
104. Thakur A, Sidu RK, Zou H, Alam MK, Yang M, Lee Y. Inhibition of Glioma Cells' Proliferation by Doxorubicin-Loaded Exosomes via Microfluidics. Int $J$ Nanomed (2020) 15:8331-43. doi: 10.2147/IJN.S263956

105. Zeng A, Wei Z, Yan W, Yin J, Huang X, Zhou X, et al. Exosomal Transfer of miR-151a Enhances Chemosensitivity to Temozolomide in Drug-Resistant Glioblastoma. Cancer Lett (2018) 436:10-21. doi: 10.1016/j.canlet. 2018.08.004

106. Xu H, Zhao G, Zhang Y, Jiang H, Wang W, Zhao D, et al. Mesenchymal Stem Cell-Derived Exosomal microRNA-133b Suppresses Glioma Progression via Wnt/beta-Catenin Signaling Pathway by Targeting EZH2. Stem Cell Res Ther (2019) 10(1):381. doi: 10.1186/s13287-019-1446-Z

107. Tang H, Liu Q, Liu X, Ye F, Xie X, Xie X, et al. Plasma miR-185 as a Predictive Biomarker for Prognosis of Malignant Glioma. J Cancer Res Ther (2015) 11(3):630-4. doi: 10.4103/0973-1482.146121

108. Thakur A, Qiu G, Xu C, Han X, Yang T, NG SP, et al. Label-Free Sensing of Exosomal MCT1 and CD147 for Tracking Metabolic Reprogramming and Malignant Progression in Glioma. Scie Adv (2020) 6(26):eaaz6119. doi: 10.1126/sciadv.aaz6119

109. Xu C, Thakur A, Li Z, Yang T, Zhao C, Li Y, et al. Determination of Glioma Cells' Malignancy and Their Response to TMZ via Detecting Exosomal BIGH3 by a TiO2-CTFE-AuNIs Plasmonic Biosensor. Chem Eng J (2021) 415:128948. doi: 10.1016/j.cej.2021.128948

110. Filipazzi P, Bürdek M, Villa A, Rivoltini L, Huber V. Recent Advances on the Role of Tumor Exosomes in Immunosuppression and Disease Progression. Seminars Cancer Biol (2012) 22:342-49. doi: 10.1016/j.semcancer. 2012.02.005

111. Graner MW, Alzate O, Dechkovskaia AM, Keene JD, Sampson JH, Mitchell DA, et al. Proteomic and Immunologic Analyses of Brain Tumor Exosomes. FASEB J (2009) 23(5):1541-57. doi: 10.1096/fj.08-122184

112. Harshyne LA, Nasca BJ, Kenyon LC, Andrews DW, Hooper DC. Serum Exosomes and Cytokines Promote a T-Helper Cell Type 2 Environment in the Peripheral Blood of Glioblastoma Patients. Neuro-Oncology (2016) 18:206-15. doi: 10.1093/neuonc/nov107

113. Murgoci AN, Cizkova D, Majerova P, Petrovova E, Medvecky L, Fournier I, et al. Brain-Cortex Microglia-Derived Exosomes: Nanoparticles for Glioma Therapy. ChemPhysChem (2018) 19:1205-14. doi: 10.1002/ cphc.201701198

114. Bu N, Wu H, Sun B, Zhang G, Zhan S, Zhang R, et al. Exosome-Loaded Dendritic Cells Elicit Tumor-Specific CD8 + Cytotoxic T Cells in Patients With Glioma. J Neuro-Oncol (2011) 104:659-67. doi: 10.1007/s11060-011-0537-1

115. Hellwinkel JE, Redzic JS, Harland TA, Gunaydin D, Anchordoquy TJ, Graner MW. Glioma-Derived Extracellular Vesicles Selectively Suppress Immune Responses. Neuro-Oncology (2016) 18:497-506. doi: 10.1093/ neuonc/nov170

116. Liu ZM, Wang YB, Yuan XH. Exosomes From Murine-Derived Gl26 Cells Promote Glioblastoma Tumor Growth by Reducing Number and Function of CD8+T Cells. Asian Pacific J Cancer Prev (2013) 14:309-14. doi: 10.7314/ APJCP.2013.14.1.309

117. De Vrij J, Niek Maas SL, Kwappenberg KMC, Schnoor R, Kleijn A, Dekker L, et al. Et Al: Glioblastoma-Derived Extracellular Vesicles Modify the Phenotype of Monocytic Cells. Int J Cancer (2015) 137:1630-42. doi: $10.1002 / \mathrm{ijc} .29521$

118. Walker S, Busatto S, Pham A, Tian M, Suh A, Carson K, et al. Extracellular Vesicle-Based Drug Delivery Systems for Cancer Treatment. Theranostics (2019) 9:8001-7. doi: 10.7150/thno.37097

119. Vleeschouwer SD, Bergers G. Glioblastoma: To Target the Tumor Cell or the Microenvironment? Codon Publications (2017) 315-40. doi: 10.15586/ codon.glioblastoma.2017.ch16
120. Schiffer D, Annovazzi L, Casalone C, Corona C, Mellai M. Glioblastoma: Microenvironment and Niche Concept Cancers (2019) 11(1):5. doi: 10.3390/ cancers 11010005

121. Sullivan R, Maresh G, Zhang X, Salomon C, Hooper J, Margolin D, et al. The Emerging Roles of Extracellular Vesicles as Communication Vehicles Within the Tumor Microenvironment and Beyond. Front Endocrinol (2017) 8:194. doi: 10.3389/fendo.2017.00194

122. Liu Y, Li X, Zhang Y, Wang H, Rong X, Peng J, et al. An miR-340-5pMacrophage Feedback Loop Modulates the Progression and Tumor Microenvironment of Glioblastoma Multiforme. Oncogene (2019) 38:7399415. doi: 10.1038/s41388-019-0952-x

123. Gabrusiewicz K, Li X, Wei J, Hashimoto Y, Marisetty AL, Ott M, et al. Glioblastoma Stem Cell-Derived Exosomes Induce M2 Macrophages and PD-L1 Expression on Human Monocytes. OncoImmunology (2018) 19: vi246. doi: 10.1080/2162402X.2017.1412909

124. Skottvoll FS, Berg HE, Bjørseth K, Lund K, Roos N, Bekhradnia S, et al. Ultracentrifugation Versus Kit Exosome Isolation: nanoLC-MS and Other Tools Reveal Similar Performance Biomarkers, But Also Contaminations. Future Sci OA (2018) 5(1):FSO359-9. doi: 10.4155/fsoa-2018-0088

125. Livshits MA, Khomyakova E, Evtushenko EG, Lazarev VN, Kulemin NA, Semina SE, et al. Isolation of Exosomes by Differential Centrifugation: Theoretical Analysis of a Commonly Used Protocol. Sci Rep (2015) 5 (1):17319. doi: 10.1038/srep17319

126. Iwai K, Minamisawa T, Suga K, Yajima Y, Shiba K. Isolation of Human Salivary Extracellular Vesicles by Iodixanol Density Gradient Ultracentrifugation and Their Characterizations. J Extracellular Vesicles (2016) 5:30829-9. doi: 10.3402/jev.v5.30829

127. Li K, Wong DK, Hong KY, Raffai RL. Cushioned-Density Gradient Ultracentrifugation (C-DGUC): A Refined and High Performance Method for the Isolation, Characterization, and Use of Exosomes. Methods Mol Biol (Clifton NJ) (2018) 1740:69-83. doi: 10.1007/978-1-4939-7652-2_7

128. Li P, Kaslan M, Lee SH, Yao J, Gao Z. Progress in Exosome Isolation Techniques. Theranostics (2017) 7(3):789-804. doi: 10.7150/thno.18133

129. Diaz G, Bridges C, Lucas M, Cheng Y, Schorey JS, Dobos KM, et al. Protein Digestion, Ultrafiltration, and Size Exclusion Chromatography to Optimize the Isolation of Exosomes From Human Blood Plasma and Serum. J Vis Exp (2018) 134):57467. doi: 10.3791/57467

130. Wang N, Wang Q, Du T, Gabriel ANA, Wang X, Sun L, et al. The Potential Roles of Exosomes in Chronic Obstructive Pulmonary Disease. Front Med (2021) 7:618506-6. doi: 10.3389/fmed.2020.618506

Conflict of Interest: The authors declare that the research was conducted in the absence of any commercial or financial relationships that could be construed as a potential conflict of interest.

Publisher's Note: All claims expressed in this article are solely those of the authors and do not necessarily represent those of their affiliated organizations, or those of the publisher, the editors and the reviewers. Any product that may be evaluated in this article, or claim that may be made by its manufacturer, is not guaranteed or endorsed by the publisher.

Copyright $\odot 2021 \mathrm{Wu}$, Wang, Wang, Hao, Liu, Wang, Yang and Lu. This is an openaccess article distributed under the terms of the Creative Commons Attribution License (CC BY). The use, distribution or reproduction in other forums is permitted, provided the original author(s) and the copyright owner(s) are credited and that the original publication in this journal is cited, in accordance with accepted academic practice. No use, distribution or reproduction is permitted which does not comply with these terms. 